
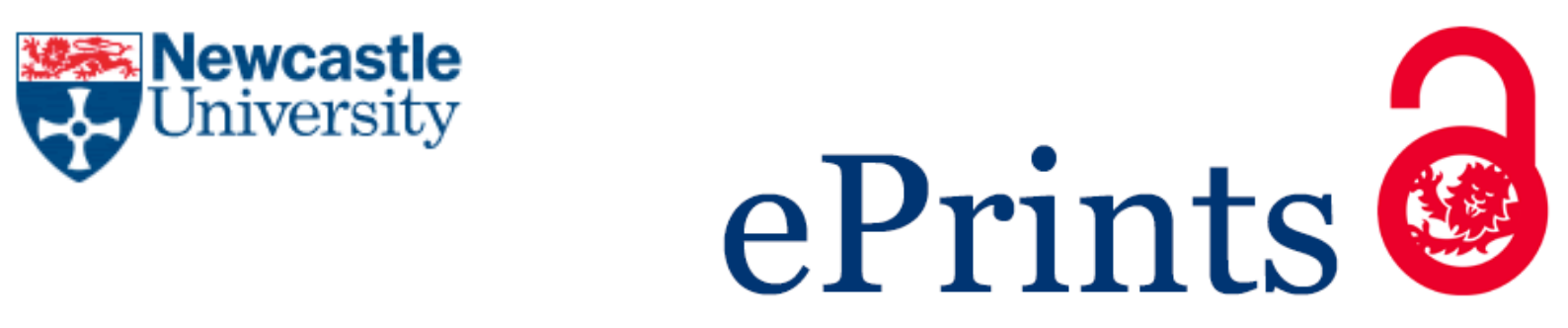

Fieber KD, Davenport IJ, Ferryman JM, Gurney RJ, Becerra VM, Walker JP, Hacker JM.

CHP toolkit: case study of LAle sensitivity to discontinuity of canopy cover in fruit plantations.

IEEE Transactions on Geoscience and Remote Sensing 2016, 54(9), 5071-5085.

Copyright:

This work is licensed under a Creative Commons Attribution 3.0 License. For more information, see http://creativecommons.org/licenses/by/3.0/

DOI link to article:

http://dx.doi.org/10.1109/TGRS.2016.2550623

Date deposited:

$27 / 04 / 2016$

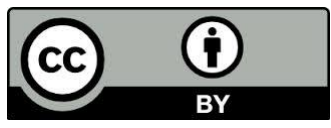

This work is licensed under a Creative Commons Attribution 3.0 Unported License 


\title{
CHP Toolkit: Case Study of LAIe Sensitivity to Discontinuity of Canopy Cover in Fruit Plantations
}

\author{
Karolina D. Fieber, Ian J. Davenport, Member, IEEE, James M. Ferryman, Member, IEEE, Robert J. Gurney, \\ Victor M. Becerra, Senior Member, IEEE, Jeffrey P. Walker, Senior Member, IEEE, and Jörg M. Hacker
}

\begin{abstract}
This paper presents an open-source canopy height profile (CHP) toolkit designed for processing small-footprint fullwaveform LiDAR data to obtain the estimates of effective leaf area index (LAIe) and CHPs. The use of the toolkit is presented with a case study of LAIe estimation in discontinuous-canopy fruit plantations. The experiments are carried out in two study areas, namely, orange and almond plantations, with different percentages of canopy cover $(48 \%$ and $40 \%$, respectively). For comparison, two commonly used discrete-point LAIe estimation methods are also tested. The LiDAR LAIe values are first computed for each of the sites and each method as a whole, providing "apparent" site-level LAIe, which disregards the discontinuity of the plantations' canopies. Since the toolkit allows for the calculation of the study area LAIe at different spatial scales, between-tree-level clumping can be easily accounted for and is then used to illustrate the impact of the discontinuity of canopy cover on LAIe retrieval. The LiDAR LAIe estimates are therefore computed at smaller scales as a mean of LAIe in various grid-cell sizes, providing estimates of "actual" site-level LAIe. Subsequently, the LiDAR LAIe results are compared with theoretical models of "apparent" LAIe versus "actual" LAIe, based on known percent canopy cover in each site. The comparison of those models to LiDAR LAIe derived from the smallest grid-cell sizes against the estimates of LAIe for the whole site has shown that the LAIe estimates obtained from the CHP toolkit provided values that are closest to those of theoretical models.
\end{abstract}

Manuscript received May 27, 2015; revised February 22, 2016; accepted March 22, 2016. Date of publication June 7, 2016; date of current version August 2, 2016. This work was supported in part by the Engineering and Physical Sciences Research Council under Grant F3322708 and Grant F4011613, by the School of Mathematical and Physical Sciences, and by the School of Systems Engineering of the University of Reading. Field campaign data were supported by the Australian Research Council through projects LE0560930, DP0557543, and FS100100040. Waveform processing was supported by the National Centre for Earth Observation, U.K.

K. D. Fieber was with the University of Reading, Reading RG6 6AY, U.K. She is now with the School of Civil Engineering and Geosciences, Newcastle University, Newcastle NE1 7RU, U.K. (e-mail: karolina.fieber@ncl.ac.uk)

I. J. Davenport is with the School of Archaeology, Geography and Environmental Sciences, University of Reading, Reading RG6 6DW, U.K.

J. M. Ferryman is with the School of Systems Engineering, University of Reading, Reading RG6 6AY, U.K.

R. J. Gurney was with the School of Mathematical and Physical Sciences, Harry Pitt Building, University of Reading, Reading RG6 6AL, U.K. He is now retired.

V. M. Becerra was with the University of Reading, Reading RG6 6AY, U.K. $\mathrm{He}$ is now with the School of Engineering, Portsmouth University, Portsmouth PO1 3DJ, U.K.

J. P. Walker is with the Department of Civil Engineering, Monash University, Clayton, Vic. 3800, Australia.

J. M. Hacker is with the Airborne Research Australia, School of the Environment, Flinders University, Adelaide, SA 5001, Australia.

Color versions of one or more of the figures in this paper are available online at http://ieeexplore.ieee.org.

Digital Object Identifier 10.1109/TGRS.2016.2550623
Index Terms-Aggregation, airborne full-waveform LiDAR, discontinuous-canopy cover, effective leaf area index (LAIe), saturation, simulation, small-footprint.

\section{INTRODUCTION}

$\mathbf{K}$ NOWLEDGE of 3-D vegetation structure and foliage amount is important for many ecological applications [1]. Such information is useful or even necessary in fire behavioral studies, flood modeling, weather forecast, environmental change [2] and carbon balance models [3], [4], as well as in forestry applications such as timber volume and biomass estimations or biodiversity studies [5], [6]. One common parameter used to describe vegetation is leaf area index (LAI). While several definitions of this index exist in the literature, the most often cited by scientists is "half the total leaf area per unit ground area" proposed by Lang et al. [7] and Chen and Black [8]. Despite the simple definition, the estimation of LAI still remains problematic [9], [10], as the only way of retrieving the true value of LAI is by harvesting. This is, however, a destructive method that is not really feasible at larger scales [9] or for long-term monitoring [11].

There are a number of indirect methods of estimating LAI, which rely on inferring that index from other variables [12], which have resulted in varying success levels in estimating LAI. They include slow laborious ground-based methods such as litter collection or hemispherical photography and faster airborne and spaceborne remote sensing methods. Each method has its respective advantages and disadvantages. For example, remote sensing techniques typically do not distinguish between woody and foliar elements of the canopy and, therefore, provide plant area index rather than LAI. Furthermore, almost all indirect techniques (with the exception of allometric equations) rely on the gap fraction methodology, which assumes a random distribution of foliage material within the tree canopy. This assumption is often invalid in reality, with the canopy elements showing a more clumpy character (particularly in coniferous trees). This, in turn, results in underestimation of LAI. Heterogeneity in foliage distribution leads to errors in LAI derived from gap fraction measurements because of the logarithmic relationship between gap fraction and LAI-an averaged variable gap fraction usually gives rise to an underestimate in LAI. Different terms have been proposed in the literature to address the aforementioned effects and their difference in relation to the true LAI. For example, some authors prefer to use the term "LAI proxy" [13]. In this paper, the effective LAI (LAIe) term, 
which was first introduced by Black et al. [14], will be used. However, contrary to the work of Black et al. [14], which used the term to address the violation of the randomness assumption only, in this study, following the work of Jonckheere et al. [2], the LAIe term is used to address the lack of correction both for the clumping effect and for woody elements of the canopy.

Clumping is a well-known effect and has been reported to occur at several scales: between plants/trees, between branches, and between shoots [9]. Several studies have proposed methods to correct the LAIe estimates from indirect (remote sensing) measurements for clumping effects [15], [16]. Despite the fact that for discontinuous canopies such as rows of crops or trees, the underestimation of LAIe is particularly pronounced [9], most of the studies only addressed between-shoot and betweenbranch clumping. However, few studies focused on clumping at the largest between-tree (or plant) scale. Lang and Yueqin [16] proposed a ground-based logarithmic averaging technique to account for gaps between rows of sorghum and wheat. The leaf area of crops was measured by averaging the transmission of direct sunlight linearly over a small horizontal distance and taking the logarithm of this mean. This method of LAI estimation provided better results than taking the mean of the transmission over the full distance. Ni-Meister et al. [17] used a hybrid geometric optical and radiative transfer (GORT) model to simulate the effects of discrete and heterogeneous canopies on large-footprint (SLICER) laser waveforms. The authors concluded that ignoring the clumping effect can significantly lower the estimates of foliage and biomass amount. Two further related studies by Ni-Meister et al. [18] and Yang et al. [19] were built on the GORT simulation model presented in the work of Ni-Meister et al. [17] and showed the light interaction with mixed and heterogeneous plant canopies.

In recent years, LiDAR technology has been found particularly well suited for describing vegetation structure [20]-[23], because of its ability to penetrate the tree canopy and its 3-D character. Much scientific discussion has been devoted to this technology, and several methods of extracting LAI have been developed. Morsdorf et al. [13] computed a LiDAR LAI proxy as a fraction of the first and last returns inside the canopy in different data trap sizes (radii between 2 and $25 \mathrm{~m}$ ) and found the best correlation with hemispherical photography for 15-m-radius traps. This was due to the large range of zenith angles $\left(0^{\circ}-60^{\circ}\right)$ used in LAI estimation from hemispherical photographs. In contrast, fractional cover defined as vegetation hits over total laser echoes was found to provide the best results for a 2-m-radius data trap with fractional cover derived from hemispherical photographs at $0^{\circ}-10^{\circ}$ angles. It was also found to be highly dependent on the size of the data trap adopted.

The main aim of this study is to present an open-source canopy height profile (CHP) toolkit as a tool to examine the influence of the discontinuity of canopy cover on LAIe retrieval from small-footprint full-waveform airborne LiDAR data. The methodology used for LiDAR processing in the CHP toolkit has previously been compared with hemispherical photography with $R^{2}$ of 0.83 at the site level [24]. The LAIe estimates produced by the CHP toolkit are also compared with the performance of discrete-point methods of LAIe estimation, including their susceptibility to saturation. The impact of the aggregation

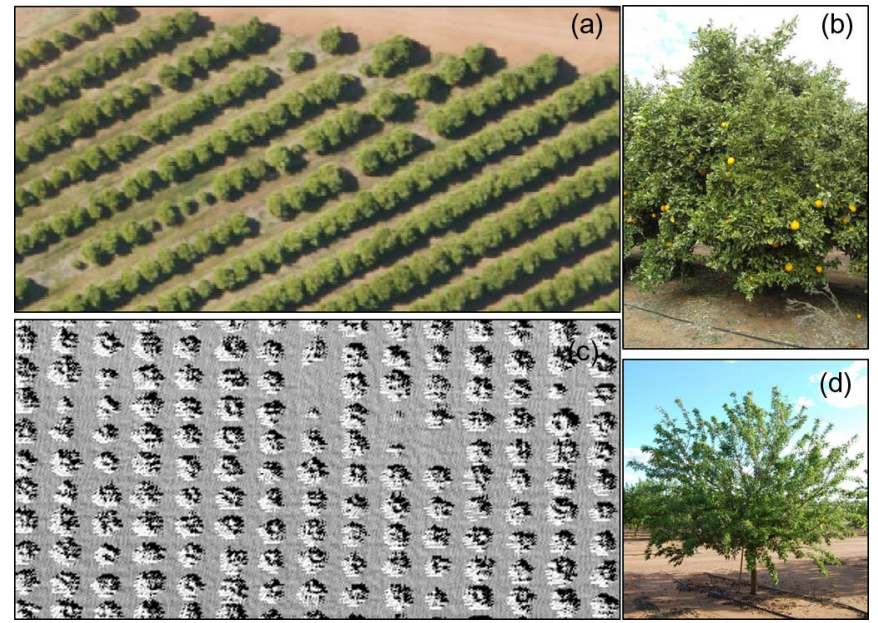

Fig. 1. Areas of interest. (a) Orange orchard aerial photography. (b) Orange tree. (c) Almond orchard shaded relief. (d) Almond tree.

area of LiDAR data is investigated by computing the LAIe in decreasing grid-cell sizes in two study areas with different percentages of crown coverage. Consequently, the difference between the "apparent" (disregarding between tree clumping, whole site) and "actual" (accounting for canopy discontinuity, 2.5-m cells) LAIe of each study area was indicated. At the same time, the benefits of small-footprint laser data for LAIe estimation in discontinuous-canopy environments were highlighted. The results of LiDAR LAIe estimation of each method were compared with a theoretical model and revealed the relative suitability of each method for LAIe estimation of discontinuous canopies.

\section{STUdy AREA}

To test the effect of the canopy discontinuity on LAIe retrieval, two study areas were selected. Both study areas are located near the town of Yanco, within the Murrumbidgee catchment, New South Wales, Australia. The first study area is a $100 \mathrm{~m} \times 50 \mathrm{~m}$ area of orange orchard located between 393400 and $393500 \mathrm{~m}$ (Easting) and between 6169280 and $6169330 \mathrm{~m}$ (Northing) (UTM, zone $55 \mathrm{H}$ ). Ground elevation in the orange orchard ranges from 122 to $125 \mathrm{~m}$ above mean sea level (AMSL) across the site, with the lowest elevations in the northwest corner and rising toward the south. The orange trees are denser and taller in the southeast corner and smaller and sparser in the northwest corner [see Fig. 1(a)]. The direction of orange tree rows is from southwest to northeast (at a bearing of about $60^{\circ}$ ), and the rows are about $7 \mathrm{~m}$ apart.

The second study site is a $100 \mathrm{~m} \times 50 \mathrm{~m}$ area of almond orchard with the almond trees distributed in north-south rows with approximately 7-m spacing [see Fig. 1(c)]. The trees in each row are spaced about $5 \mathrm{~m}$ from each other. The almond orchard study area is situated between 419180 and $419280 \mathrm{~m}$ (Easting) and between 6160080 and $6160130 \mathrm{~m}$ (Northing) (UTM, zone $55 \mathrm{H}$ ). The ground elevation varies from 144 to $146 \mathrm{~m}$ AMSL across the site, with the highest elevations toward the south of the site and the lowest elevations in the northwest corner. 


\section{DATA}

\section{A. LiDAR}

All laser scanning data were acquired by Airborne Research Australia with a full-waveform Riegl LMS-Q560 instrument [25] operating at 1550-nm wavelength from light aircraft. The orange orchard data were acquired on November 3, 2006 as part of the National Airborne Field Experiment 2006-NAFE'06 [26]. The flying altitude was $500 \mathrm{~m}$ above ground level, resulting in a $0.25-\mathrm{m}$ footprint size. The average laser shot density was 4 per $\mathrm{m}^{2}$ with an average point density (after a custom decomposition procedure) of 6.5 points per $\mathrm{m}^{2}$. The laser altimetry data were captured along a $75-\mathrm{km}$-long transect line across the Yanco site. The almond orchard data were acquired on September 22, 2011 as part of The Third Soil Moisture Active Passive Experiment-SMAPEx-3 [27]. The flying altitude was around $400 \mathrm{~m}$ for the almond orchard, providing a beam footprint of $0.20 \mathrm{~m}$. The average laser shot density was 6.3 per $\mathrm{m}^{2}$, and the average point density (after the custom decomposition procedure) was 9.7 points per $\mathrm{m}^{2}$ in the almond orchard area. In both data sets, both transmitted and received waveforms were recorded and sampled with a frequency of $1 \mathrm{GHz}$ ( $1 \mathrm{~ns}$ corresponding to $\sim 15-\mathrm{cm}$ vertical resolution).

\section{B. Other Data}

Aerial photography was taken using an 11-MP Canon EOS-1Ds digital camera fitted with a 34-mm lens, mounted on the same aircraft during the LiDAR acquisition in 2006, providing high-resolution imagery over the orange orchard focus area. The ground pixel size of those images was about $15 \mathrm{~cm}$. The aerial image of the site was rectified for the purpose of providing ground reference data. The orange tree crowns were manually delineated on the rectified image and the percent crown cover in the study area calculated, yielding $48.2 \%$ cover. In total, 206 trees (or partial trees) were delineated, with a single crown area ranging from 1.4 to $20.5 \mathrm{~m}^{2}$. The mean crown area disregarding incomplete trees on the edges of the area of interest yielded $12.5 \mathrm{~m}^{2}$ corresponding to a crown radius of about $2.0 \mathrm{~m}$ (area standard deviation of $2.4 \mathrm{~m}^{2}$ ).

Since there was no high-resolution aerial photography available for the almond orchard scene (the photography taken was of too low resolution for this purpose), the shaded relief image [see Fig. 1(c)] generated from LiDAR data was used as a base for manual delineation of the crowns. In total, 160 trees (or partial trees) were delineated with a single crown area ranging from 1.8 to $19.5 \mathrm{~m}^{2}$. The mean crown area disregarding incomplete trees on the edges of the area of interest yielded $13.1 \mathrm{~m}^{2}$ (which corresponds to a $2-\mathrm{m}$ crown radius) with a standard deviation of $2.2 \mathrm{~m}^{2}$. The percent crown cover in this study area was $40.0 \%$.

\section{METHODS}

\section{A. LAIe Estimation}

The techniques for LAIe extraction from LiDAR data used in this study can be divided into two groups: 1) raw waveform methods and 2) discrete-point methods. The methodology used in the CHP toolkit is a raw waveform method. In the second group, two ways of determining gap probability from point cloud information were examined. LAIe estimates were extracted for the study areas as a whole, by processing total blocks of data $(100 \mathrm{~m} \times 50 \mathrm{~m})$ at once, providing the "apparent" LAIe of each site (disregarding canopy discontinuity). The computation was also performed in various decreasing grid-cell sizes by dividing each study area into uniform square grid cells $(50,25,10,5,2.5,2$, and $1 \mathrm{~m})$, calculating LAIe for each cell and averaging across the whole site to provide one comparable site-level estimate.

Hemispherical photographs or LAI-2000 measurements were not taken at the time of LiDAR overpass at either of the sites; however, the methodology used in the CHP toolkit has previously been compared with the use of hemispherical photography in a sparse forest canopy providing a high correlation of 0.83 at the site-level [24]. The discrete-point ratios have also been widely studied and validated [11], [13], [28]-[30]. In this paper, a comparison to a theoretical model will be used as a way of validation.

As a result of gridding, the estimation of LAIe for a very few cells in the smallest grids saturated due to the lack of light returned from the ground (while returns from vegetation existed), making it impossible to calculate the gap fraction. This effect is well known to appear in both LiDAR and optical data based on LAIe estimation [10], [31]. Richardson et al. [10] discussed possible solutions to avoid this effect in LiDAR discrete-point data estimates, such as increasing point density, increasing aggregation cell size, taking into account the angle of incidence of individual pulses, and configuring the detection process for lower energy reflections. One simple solution would be to set the number of ground returns to the minimum value of 1 [10], which would consequently cause some underestimation of LAIe. Furthermore, the error of underestimation would increase with increasing footprint and decreasing gridcell size. Nevertheless, this is a simple solution only in the case of discrete-point methods. In the waveform methodology, this would mean creating an artificial ground waveform, which is not easily implemented due to energy variation between the laser shots. In this paper, to enable calculation of mean LAIe for the whole area, the maximum LAIe cell value in the data set was found prior to averaging across the site and assigned to all saturated cells in that data set. Although this is not an ideal solution, it was the only practical option to implement for all LAIe estimation methods and enabled the calculation of LAIe of the study areas.

1) CHP Toolkit: CHP toolkit [32] is a free open-source software developed at the University of Reading, U.K. The program uses the open-source PulseWaves [33] data format, and it is designed to convert relatively small raw full-waveform small-footprint LiDAR data sets over vegetated areas into LAIe and CHPs. The waveform processing method used in the CHP toolkit is based on an adaptation of the SLICER CHP procedure presented in the work of Harding et al. [20] to small-footprint LiDAR data [24], where LAIe is estimated as one of the stages in the procedure. The CHP methodology is described in detail in [24] and consists of aligning the data relative to ground level, calculating the returned energy profile taking into account the 
vegetation-ground reflectance ratio, converting it into a canopy closure profile, then into a leaf area profile, and finally into a CHP. The procedure does not require a fully optimized decomposition of the data; only the approximate (initial) location of the first and last pulses within the waveform and a digital terrain model (DTM) are needed.

The CHP toolkit consists of four modules. Module 1 reads the PulseWaves format data, provides some basic information about the data, and converts the data in a selected area into an ASCII file. Module 2 reads the newly created ASCII file and performs simple peak detection to locate the peaks and to estimate their amplitude and width in the returned waveform data. Module 3 uses the point cloud data from Module 2 to filter ground points from single returns and from last returns. Finally, Module 4 processes previously generated files using the CHP methodology to obtain LAIe estimates (WF1) as well as CHPs. The reflectance ratio used to scale ground return is estimated via the technique proposed by Armston et al. [34], unless it is not possible to calculate it. Full documentation of the software is available online [32].

2) Point Methods: To compare the performance of the rawwaveform method and the discrete-point ratio LAIe estimation method, the waveforms were extracted using the GeoCodeWF commercial software, calibrated and decomposed using a custom Gaussian decomposition procedure with a trust-regionreflective algorithm. The details of the decomposition and calibration procedures can be found in [35]. The decomposition produced point clouds with information for each point, including easting, northing, elevation, amplitude, pulsewidth, peak position within the waveform train, pulse number within the waveform, number of pulses per waveform, angle of incidence, and backscattering coefficient [36]. Subsequently, single-peakper-waveform points, classified into ground and vegetation using the backscattering coefficient, were used to build a DTM for each of the sites. The DTM was then subtracted from the point clouds to provide each point with its elevation above ground level.

The point clouds extracted in the process of custom Gaussian decomposition (as described in [35]) were analyzed to provide a discrete-point LAIe derived from gap probability. Two point methods of LAIe extraction were tested in the area of interest. Both of the methods rely on gap fraction but use different gap probability $(\mathrm{P})$ ratios. In the first method (PT1), the ratio is defined as the number of single-return waveforms returned from the ground $S_{g}$ ( $<0.5 \mathrm{~m}$ above ground) to the total number of waveforms within the grid cell $N_{\mathrm{WF}}$ [37], [38]. Thus

$$
P=\frac{S_{g}}{N_{\mathrm{WF}}} \text {. }
$$

The second point method (PT2) uses the ratio of the number of all ground points $N_{g}$ ( $<0.5 \mathrm{~m}$ above ground) to the sum of ground and vegetation $\left(N_{v}\right)$ returns in the grid cell [28]. This method is also equivalent to fractional cover used by Morsdorf et al. [13], with the difference that the threshold used to separate ground and vegetation returns in that study was $1.25 \mathrm{~m}$. Thus

$$
P=\frac{N_{g}}{N_{g}+N_{v}} .
$$

The above ratios in point methods are then used to calculate LAIe based on Aber's [39] equation, i.e.,

$$
\mathrm{LAI}_{e}=-\ln (P) \text {. }
$$

\section{B. Theoretical Model}

Due to the lack of hemispherical photography or LAI-2000 measurements, the results of LiDAR LAIe were verified against a theoretical model. The theoretical model represents corrected LAI with a needle-to-shoot ratio of 1 published by Chen et al. [15].

The percent canopy cover values of $40 \%$ in the almond orchard and $48 \%$ in the orange orchard, estimated based on aerial photography and shaded relief, were used to simulate theoretical study area LAIe for the two cases of taking into account the discontinuity of the canopy cover ("actual" LAIe) and disregarding it ("apparent" LAIe). The simulation was performed based on a range of average single-tree LAI LAIe $T$ values (from 0.2 to 10 with increments of 0.1 ) and known vegetation fraction cover $\left(A_{T}\right)$. The "actual" LAIe $\left(\mathrm{LAIe}_{\mathrm{ACT}}\right)$ is the product of the average single tree $\mathrm{LAIe}_{T}$ and the fraction of the area covered by the tree crowns $A_{T}$, i.e.,

$$
\mathrm{LAIe}_{\mathrm{ACT}}=\mathrm{LAIe}_{T} A_{T} .
$$

The simulated "apparent" LAIe disregarding the effect of canopy discontinuity was obtained by calculating LAIe for the whole study area from summed up probabilities of penetration for the tree-covered area $\left(P_{\text {gap }}=e^{-\mathrm{LAIe}_{T}}\right)$ and bare-soil area $\left(P_{\text {gapG }}=1\right)$ according to

$$
\begin{aligned}
\mathrm{LAIe}_{\mathrm{APP}} & =-\ln \left(\frac{P_{\mathrm{gapT}} A_{T}+P_{\mathrm{gapG}} A_{G}}{A_{T}+A_{G}}\right) \\
& =-\ln \left(P_{\mathrm{gapT}} A_{T}+A_{G}\right)
\end{aligned}
$$

where $A_{G}=1-A_{T}$ is the fraction of the area not covered by vegetation.

\section{RESUlTS AND DISCUSSION}

Fig. 2 presents the relationship between the integrated vegetation $\left(R_{v}\right)$ and ground $\left(R_{g}\right)$ returns calculated according to the methodology of Armston et al. [34] and provided by the CHP toolkit in both study sites in 1-, 2-, 2.5-, and 5-m cells. These plots show a linear relationship between the integrals and confirm that the assumption of constant vegetation and ground reflectance relation is valid for both study sites. A theoretical reflectance ratio between vegetation and soil at the 1550-nm wavelength used by Riegl LMS-Q560 should be around 0.5, which means that soil is twice as reflective as vegetation at this wavelength. The exact value will depend on the reflective properties of vegetation species and soil types. In the orange orchard, this ratio was determined to be slightly above the default value (0.56), whereas in the almond orchard, it was found to be lower $(0.41)$. This suggests that assuming the soil properties are similar in both sites-in the Yanco area, loams composed of sand, silt, and clay dominate [40]—almond trees are less reflective than orange trees at $1550-\mathrm{nm}$ wavelength.

Fig. 3 presents the relationship between LAIe and gridcell size for both study sites, whereas Tables I and II list the 

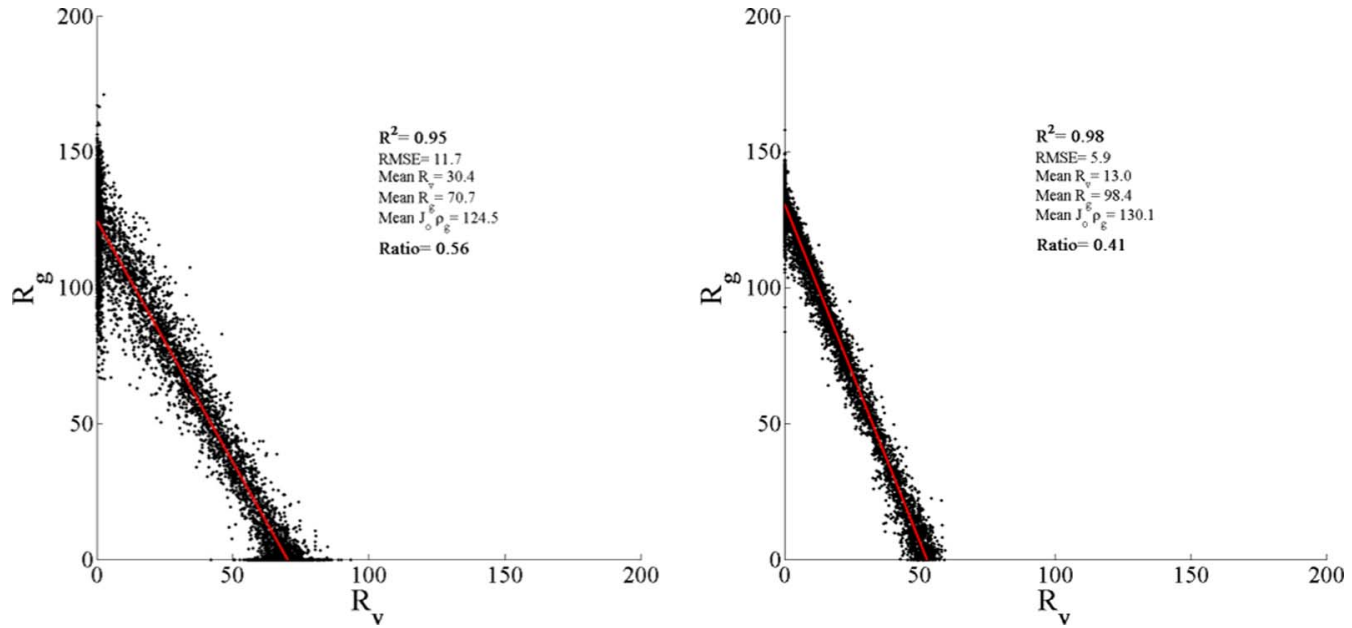

Fig. 2. Relationship between integrated vegetation $\left(R_{v}\right)$ and ground $\left(R_{g}\right)$ returns (a) in the orange orchard and (b) in the almond orchard. $R_{v}$ and $R_{g}$ values calculated by the CHP toolkit in 1-, 2-, 2.5-, and 5-m grid cells.

TABLE I

Percent of Saturated Cells in Orange Orchard, WHERE LAIE IS IMPOSSIBLE TO CALCULATE

\begin{tabular}{cccc}
\hline Grid cell size & WF1 & PT1 & PT2 \\
\hline $\mathbf{1 0 m}$ & 0 & 0 & 0 \\
$\mathbf{5 m}$ & 0 & 0 & 0 \\
$\mathbf{2 . 5 m}$ & $2.3 \%$ & $12 \%$ & $1.6 \%$ \\
$\mathbf{2 m}$ & $6.4 \%$ & $19 \%$ & $5 \%$ \\
$\mathbf{1 m}$ & $23 \%$ & $37 \%$ & $22 \%$ \\
\hline
\end{tabular}

TABLE II

Percent of Saturated Cells in Almond Orchard, WHERE LAIE IS IMPOSSIBLE TO CALCULATE

\begin{tabular}{cccc}
\hline Grid cell size & WF1 & PT1 & PT2 \\
\hline $\mathbf{1 0 m}$ & 0 & 0 & 0 \\
$\mathbf{5 m}$ & 0 & 0 & 0 \\
$\mathbf{2 . 5 m}$ & 0 & $0.1 \%$ & \\
$\mathbf{2} \mathbf{m}$ & 0 & $4.6 \%$ & 0 \\
$\mathbf{1 m}$ & $0.6 \%$ & $18 \%$ & $0.5 \%$ \\
\hline
\end{tabular}

percentage of saturated cells in them. From the plots in Fig. 3, one can notice that LAIe estimates for cells $5 \mathrm{~m}$ and larger are almost constant for all methods. The trees in both sites have an average radius of about $2 \mathrm{~m}$, which means that using a cell of $5 \mathrm{~m}$ and larger will not resolve the heterogeneity of the studied sites as the cells will have mixtures of vegetation and bare soil within them. It seems therefore that using a $5-\mathrm{m}$ or a $50-\mathrm{m}$ LiDAR aggregation area will provide similar estimates of LAIe in the studied plantations. It is expected that with the decreasing grid-cell size, the overall study area LAIe will increase. This is due to the fact that the smaller the cells are, the more homogenous is the area within them (either fully covered with vegetation or ground), resulting in a higher average estimate across the overall study area. Plots in Fig. 3 confirm that for the grid-cell sizes smaller than $5 \mathrm{~m}$, the estimates start to change dramatically.

In the case of the waveform method with estimates from the CHP toolkit, the tendency of increasing LAIe with decreasing grid-cell size is consistent. Table I shows, however, relatively high saturation $(23 \%)$ of the 1-m cell estimates and some small saturation of 2-m (6.4\%) and 2.5-m (2.3\%) cells in the orange orchard. In the almond orchard, the saturation of WF1 is almost none-only $0.6 \%$ cells saturated in 1 -m cell estimation. The difference in saturation levels is related to the density of foliage (orange trees seem denser than almond trees) as well as to the laser point density, which was higher in the almond orchard (6.3 shots per $\mathrm{m}^{2}$ as opposed to 4 shots per $\mathrm{m}^{2}$ in the orange orchard). The waveform method does not rely on the number of points extracted (it uses the raw light curve), and it takes into account the radiometric properties of the target. It is therefore capable of yielding higher single-cell LAIe values, further indicating that this method may be suited for LAIe retrieval in fruit plantations with discontinuous-canopy cover on the condition that an appropriate cell size is chosen.

The discrete-point method PT1 (using only single returns) shows the tendency to have higher LAIe values for $2.5-\mathrm{m}$ cells (in comparison to 5-m cells and larger), whereas for 2- and 1-m cells, the estimates stabilize and even drop in the orange orchard. In the almond orchard, the increase is visible throughout; its rate, however, is not very consistent. This is likely due to the highest level of saturation of that method summarized in Tables I and II. The PT1 method uses only waveforms containing a single ground or vegetation return, which means that the point density is decreased. This, in turn, makes the method more prone to saturation (reaching $37 \%$ in $1-\mathrm{m}$ cells in the orange orchard and $18 \%$ in $1-\mathrm{m}$ cells in the almond orchard). Therefore, the smaller the grid, the more likely it is that there will be no ground return present in that cell. It is clear that PT1 is the method that saturates the easiest, and its estimates from the smallest cells will be biased. It is therefore not particularly suitable for LAIe estimates in fruit plantations with a discontinuous canopy, particularly if the point density is not very high.

The discrete-point method PT2 (using all returns) shows only a slight increase of its values with decreasing cell size in the orange orchard study site, whereas in the almond orchard, the estimates drop altogether for all of the smallest cells (see Fig. 3). One possible explanation for this anomalous behavior lies in the foliage density of the almond trees. As shown in 
(a)

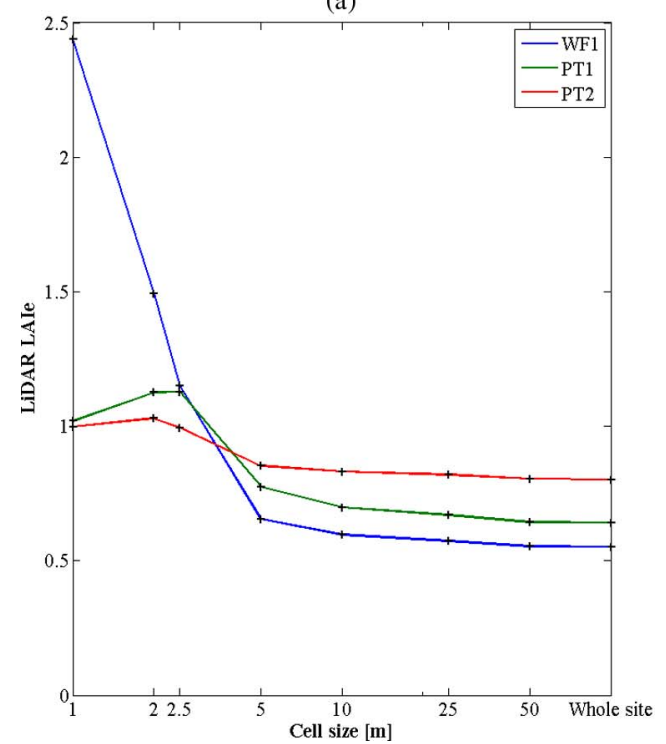

(b)

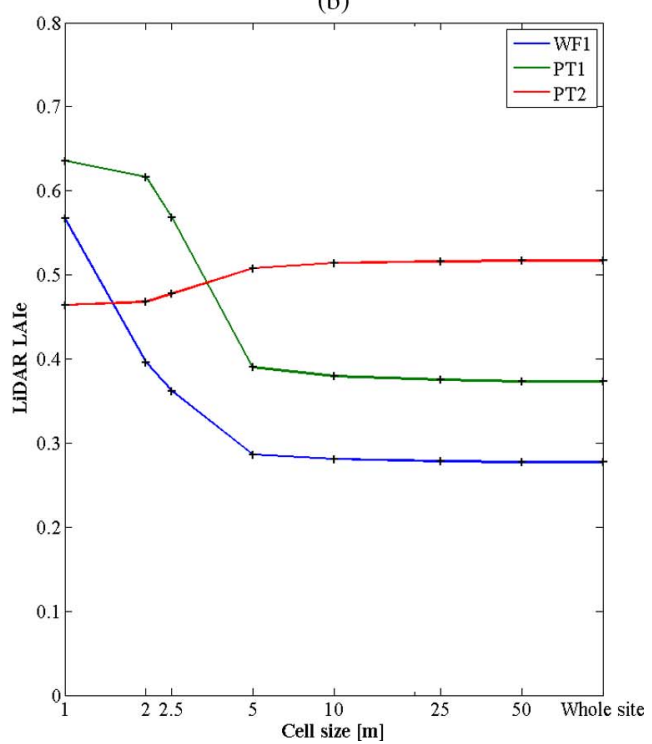

Fig. 3. LAIe of the site depending on the grid-cell size used (logarithmic scale). (a) Orange orchard site. (b) Almond orchard site. The LAIe of 2-m cells is considered to be "actual," whereas that of larger cells is "apparent" (see text for further information).

Fig. 1, almond trees have less dense foliage than orange trees and, therefore, allow more pulses to penetrate their canopies. The nature of the PT2 method is such that it disregards the area of pulse interaction with the target and treats all the points equally. The leaves are small and sparse enough that the laser gets some ground return in each waveform. Therefore, for almond trees, more pulses partially transmit through their canopy and reach the ground, increasing the number of ground points detected. As a result, the percentage of ground points relative to all detected points increases with the decrease in grid-cell size, causing the LAIe of the cell to drop. In consequence, this particular method shows an inverse relationship (decrease in LAIe instead of increase) while the cells become more homogenous. Thus, PT2 does not seem to be suitable for LAIe estimates of discontinuous canopies with scattered foliage elements smaller than the laser footprint.

If we now consider that LiDAR estimates of LAIe for the study site as a whole correspond to the "apparent" LAIe that disregards the heterogeneity of the area [expressed by (5)] and that LiDAR LAIe site-level estimates from 5-m cells and smaller are our "actual" LAIe estimates, a comparison can be made to a theoretical model of "actual" versus "apparent" LAIe (see Fig. 4). This comparison is presented in Fig. 5. The difference in the LAIe calculated using these two equations presented in Section IV-B has an exponential character and increases with the increasing LAIe of an average single tree (see Fig. 4). The "apparent" LAIe asymptotically approaches a specific value with increasing "actual" LAIe for each crown coverage percentage.

The "apparent" LAIe of the theoretical model in the orange orchard site (48\% of canopy cover) clearly saturates around the value of 0.65 [black dotted line in Fig. 5(a)] corresponding to the "actual" mean site LAIe of around 2.2 and an average single-tree LAIe of 4.6. Both LiDAR point methods provided “apparent" LiDAR LAIe estimates $(100 \mathrm{~m} \times 50 \mathrm{~m}$ site $)$ either equal to (PT1) or much higher (PT2) than that value of saturation, causing a clear lack of correspondence with the theoretical model in the orange orchard site for those methods. Moreover, to match the theoretical model, PT2's "apparent" LiDAR LAIe estimate of 0.80 in the orange orchard would have to correspond to about $80 \%$ canopy cover in the site. This implies that the PT2 method is not well suited for discontinuouscanopy environments. In the case of PT1, the estimates are closer to the theoretical model; however, the high level of saturation makes the "actual" estimates of 2.5-m cells and smaller not reliable, whereas estimates of larger cells disregard the heterogeneity of the site underestimating the "actual" LAIe value. The waveform method provides the most plausible LiDAR LAIe values in the orange orchard. The LiDAR sitelevel "actual" LAIe estimate of 1.15 in 2.5 -m grid-cell size achieved the best match with the theoretical model in a site with $48 \%$ crown coverage. This corresponds to an average singletree LAIe value of 2.4. The LiDAR LAIe WF1 values from 1 - and 2-m cells overestimated the "actual" theoretical LAIe. This, particularly being the case for $1-\mathrm{m}$ cell size, is likely related to the $23 \%$ saturation of LAIe estimates and leads to bias toward higher values due to the fact that the cells with no ground return were assigned a value of the highest calculated grid-level LAIe in the data set (LAIe of 8.3).

In the almond orchard ( $40 \%$ crown coverage), the theoretical model saturates at an apparent LAIe value of 0.51 . This corresponds to the "actual" theoretical LAIe of about 2 and an average single-tree LAIe of 5. As shown in Fig. 5(b), PT2 once again provides estimates that do not match the theoretical model. Against the forecast, particularly given that there is almost no saturation present, the smallest grid LAIe estimates yield lower values than those of larger cells. This once again confirms the lack of suitability of this method for LAIe estimation in discontinuous canopies of fruit plantations. The PT1 method has provided estimates that match the theoretical model better in the almond orchard than in the orange orchard. In particular, the estimates of $2.5-\mathrm{m}$ cells have matched the 


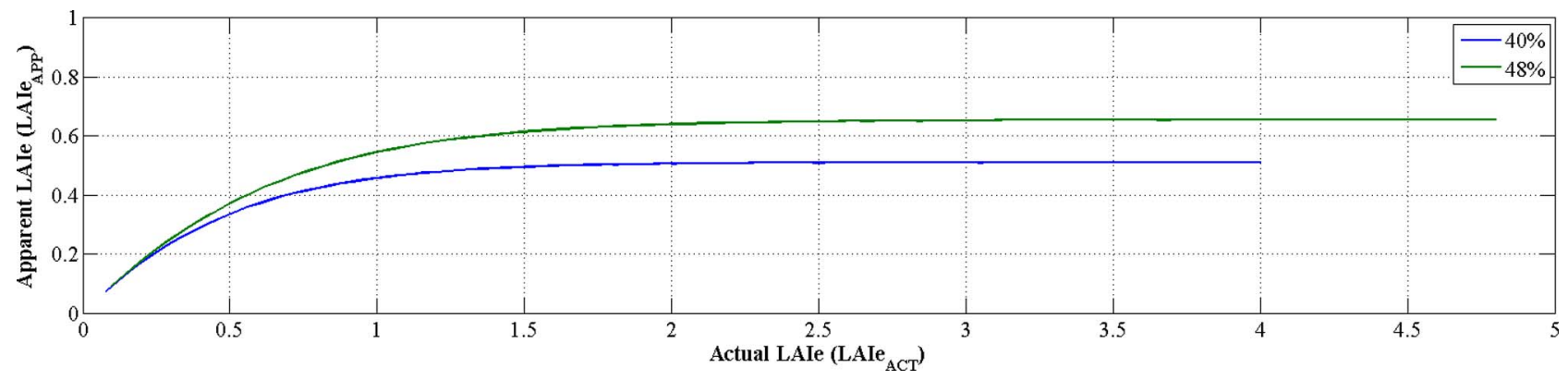

Fig. 4. Theoretical relationship between simulated "apparent" LAIe and "actual" LAIe of a study site depending on the crown coverage of $40 \%$ or $48 \%$.

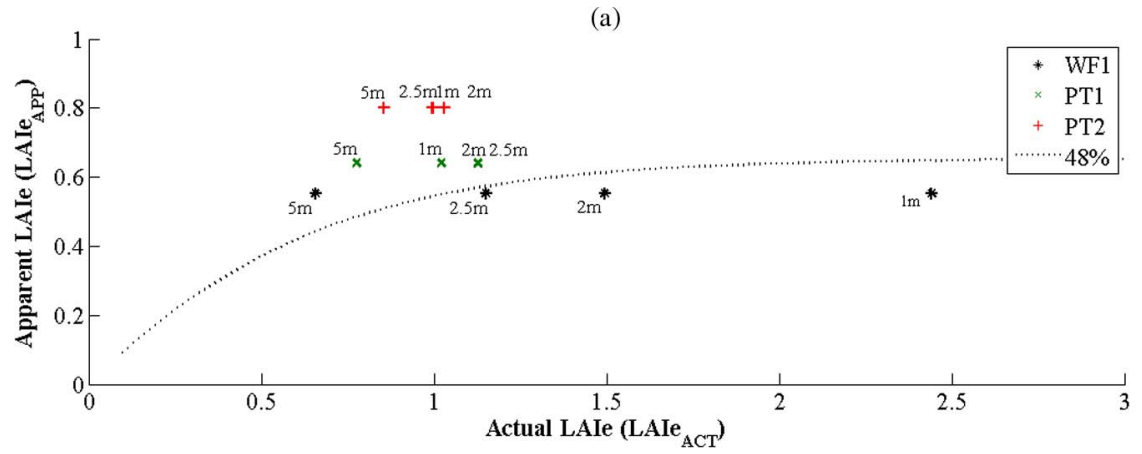

(b)

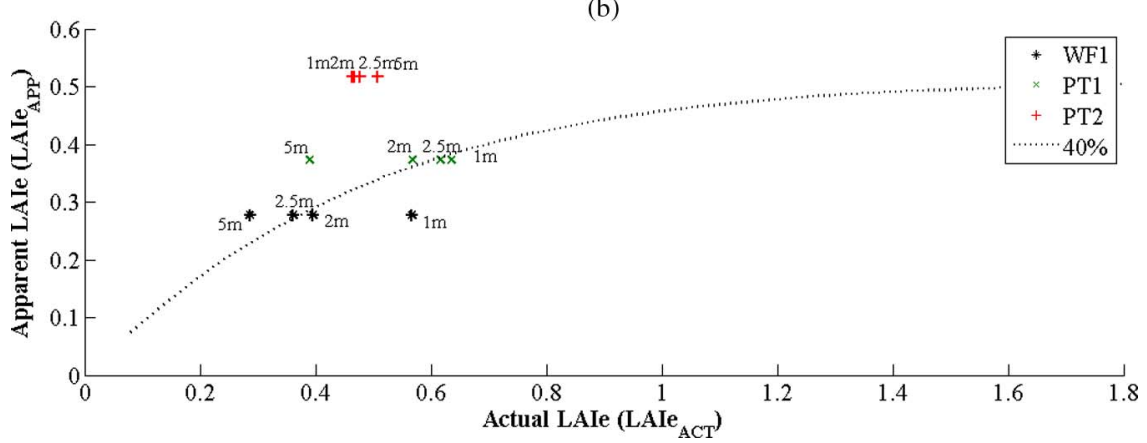

Fig. 5. Comparison of LiDAR "actual" versus "apparent" LAIe to theoretical model for (a) the orange orchard and (b) the almond orchard.

model well. This method, however, remains the most prone to saturation with $18 \%$ of the $1-\mathrm{m}$ cells and almost $5 \%$ of the 2-m cells saturated, while none of the cells at this size saturated in WF1 and PT2. Similarly to the orange orchard site, in the almond orchard, the waveform method provided the results best matching the theoretical model, particularly for 2.5-m cells (although 2-m cell estimation was also very close). Once again, $1-\mathrm{m}$ estimates proved to overestimate the "actual" theoretical model.

The results in both study sites showed that the spatial resolution matching the theoretical model best is sampling with 2.5-m grid-cell size. From the perspective of spatial uniformity, it seems that the smaller the pixel (grid cell) size, the better the estimate of the LAIe should be as each cell contains more homogenous vegetation. However, as the above results have shown, there is some risk of saturation (determined mostly by the point density), and therefore, results can be biased for the smallest grid-cell sizes. It is thus crucial to take into account both the characteristics of the vegetation in the study area as well as the limitations in the LiDAR LAIe methods while choosing the sampling size. Since the tree crowns in both study sites are, on average, about $4 \mathrm{~m}$ in diameter, it is sensible to choose a smaller grid-cell size to depict the heterogeneity of the sites, perhaps around half the tree crown diameter. In the study sites tested, this value turned out to be $2.5 \mathrm{~m}$ (as 2-m cells slightly saturated in the orange orchard). This is in agreement with the Nyquist-Shannon sampling theorem, suggesting that the sampling needs to be done twice as fast as the measured function changes [41].

\section{CONCLUSION}

This study has presented the use of an open-source CHP toolkit for the estimation of LAIe in a discontinuous-canopy environment of fruit plantations. The performance of the rawwaveform method of the CHP toolkit was confronted with two commonly used discrete-point ratios. It was shown that disregarding the canopy discontinuity may lead to considerable underestimation of the study area LAIe, the degree of which will depend on the LAIe of the trees as well as the percent crown cover within the study area. Furthermore, by examining the mean study area LAIe at different spatial scales, the study 
suggests that aggregation to larger footprints (or large-footprint laser scanning data) may not be suitable for LAIe estimation of areas with discontinuous-canopy cover without correction to account for violation of the randomness assumption. Thus, whether the footprint is of $5 \mathrm{~m}$ or $50 \mathrm{~m}$, the LAIe estimate remains almost constant and considerably underestimated. Only aggregation to cells smaller than the crown diameter reduced the effect, exposing the weakness of aggregation to larger footprints for LAIe estimation in such environments.

The methods used in the study were previously compared with LAIe estimation methods such as hemispherical photography in other studies (e.g., [13], [24], and [28]). However, hemispherical photography, although commonly used, is not an ideal source of LAIe estimates as it is prone to biases and random noise related to the thresholds used to separate vegetation from sky and lacks the ability to separate between-crown and within-crown gap probabilities [13]. Airborne LiDAR in comparison can provide much better horizontal sampling and, by using the gridding method proposed in this study, can take into account heterogeneity of the study area by providing between-crown and within-crown gap probabilities.

Although the absolute verification of the results of this study was not possible due to lack of LAIe estimates from an alternative source, the comparison of the methods against a theoretical model of "actual" versus "apparent" LAIe behavior addresses some points regarding LiDAR LAIe estimation in discontinuous canopies. First of all, as expected and shown by the theoretical model, disregarding the effect of canopy discontinuity can have a severe impact on the LAIe retrieval, highly underestimating it. The lower the crown percent cover in the study area, the higher the underestimation of the "actual" LAIe will be. Second, discrete-point methods used in this study are not advisable for LAIe estimation in discontinuous-canopy environments. This is due to both their higher susceptibility to saturation (PT1 based on single-return data) and high overestimation and unstable behavior (i.e., PT2 based on all ground returns to the total return number). Third, the raw-waveform method implementation of the CHP methodology in the CHP toolkit seems to provide the most probable results of the scene LAIe, enabling an easy calculation at a desired spatial scale. The agreement of this method with the theoretical model gives some confidence in the validity of the raw-waveform approach.

Finally, this study suggests that small-footprint LiDAR data offer a unique possibility to compute the LAIe in small aggregation areas (grid cell). However, some aggregation of smallfootprint LiDAR data is unavoidable due to the nature of the data-the small cross section of those systems means that not all of the shots will reach the ground, therefore making the calculation of LAIe impossible at the individual footprint level. The decision on the size of the aggregation area should be made taking into account the density of the laser data, to avoid saturation of LAIe, as well as the characteristics of the study sites, to prevent under- and oversampling of data (tree crown sizes). The resolution should ideally be in agreement with the Nyquist-Shannon theorem, suggesting sampling twice as fast as the measured function changes, and in this case, it means that the cell size should be about half the mean crown diameter. Further work should focus on testing the toolkit in other environments including coniferous stands having different degrees of canopy percent cover and validation against other ways of LAIe estimation. Furthermore, the combined effect of the clumping effect at all levels (i.e., between-tree, betweenbranch, and between-shoot) should be investigated.

\section{ACKNOWLEDGMENT}

The authors would like to thank M. Tanase for the field trip to the orange orchard site.

\section{REFERENCES}

[1] F. Zhao et al., "Measuring effective leaf area index, foliage profile, and stand height in New England forest stands using a full-waveform groundbased lidar," Remote Sens. Environ., vol. 115, pp. 2954-2964, 2011.

[2] I. Jonckheere et al., "Review of methods for in situ leaf area index determination: Part I. Theories, sensors and hemispherical photography,' Agricult. Forest Meteorol., vol. 121, pp. 19-35, 2004.

[3] M. A. Lefsky, A. T. Hudak, W. B. Cohen, and S. A. Acker, "Geographic variability in lidar predictions of forest stand structure in the Pacific Northwest," Remote Sens. Environ., vol. 95, pp. 532-548, 2005.

[4] B. Koetz et al., "Inversion of a lidar waveform model for forest biophysical parameter estimation," IEEE Geosci. Remote Sens. Lett., vol. 3, no. 1, pp. 49-53, Jan. 2006.

[5] F. Pirotti, "Analysis of full-waveform LiDAR data for forestry applications: A review of investigations and methods," iForest-Biogeosci. Forestry, vol. 4, pp. 100-106, 2011.

[6] C. Mallet and F. Bretar, "Full-waveform topographic lidar: State-of-theart," ISPRS J. Photogramm. Remote Sens., vol. 64, pp. 1-16, 2009.

[7] A. R. G. Lang, R. E. McMurtrie, and M. L. Benson, "Validity of surface area indices of Pinus radiata estimated from transmittance of the sun's beam," Agricultural Forest Meteorol., vol. 57, no. 1-3, pp. 157-170, Dec. 1991.

[8] J. M. Chen and T. A. Black, "Defining leaf area index for non-flat leaves," Plant, Cell Environ., vol. 15, pp. 421-429, 1992.

[9] N. J. J. Breda, "Ground-based measurements of leaf area index: A review of methods, instruments and current controversies," J. Exp. Botany, vol. 54, pp. 2403-2417, Nov. 2003.

[10] J. J. Richardson, L. M. Moskal, and S.-H. Kim, "Modeling approaches to estimate effective leaf area index from aerial discrete-return LIDAR," Agricultural Forest Meteorol., vol. 149, no. 6/7, pp. 1152-1160, Jun. 2009.

[11] D. Riaño, F. Valladares, S. Condés, and E. Chuvieco, "Estimation of leaf area index and covered ground from airborne laser scanner (Lidar) in two contrasting forests," Agricultural Forest Meteorol., vol. 124, no. 3/4, pp. 269-275, Aug. 2004.

[12] P. E. Levy and P. G. Jarvis, "Direct and indirect measurements of LAI in millet and fallow vegetation in HAPEX-Sahel," Agricultural Forest Meteorol., vol. 97, no. 3, pp. 199-212, Nov. 1999.

[13] F. Morsdorf, B. Kötz, E. Meier, K. I. Itten, and B. Allgöwer, "Estimation of LAI and fractional cover from small footprint airborne laser scanning data based on gap fraction," Remote Sens. Environ., vol. 104, pp. 50-61, 2006.

[14] T. A. Black, J.-M. Chen, X. Lee, and R. M. Sagar, "Characteristics of shortwave and longwave irradiances under a Douglas-fir forest stand," Can. J. Forest Res., vol. 21, pp. 1020-1028, Jul. 1, 1991.

[15] J. M. Chen, P. M. Rich, S. T. Gower, J. M. Norman, and S. Plummer, "Leaf area index of boreal forests: Theory, techniques, and measurements," J. Geophys. Res., Atmos., vol. 102, no. D24, pp. 29429-29443, Dec. 1997.

[16] A. R. G. Lang and X. Yueqin, "Estimation of leaf area index from transmission of direct sunlight in discontinuous canopies," Agricultural Forest Meteorol., vol. 37, no. 3, pp. 229-243, Aug. 1986.

[17] W. Ni-Meister, D. L. B. Jupp, and R. Dubayah, "Modeling lidar waveforms in heterogeneous and discrete canopies," IEEE Trans. Geosci. Remote Sens., vol. 39, no. 9, pp. 1943-1958, Sep. 2001.

[18] W. Ni-Meister, W. Yang, and N. Y. Kiang, "A clumped-foliage canopy radiative transfer model for a global dynamic terrestrial ecosystem model. I: Theory," Agricultural Forest Meteorol., vol. 150, no. 7/8, pp. 881-894, Jul. 2010.

[19] W. Yang et al., "A clumped-foliage canopy radiative transfer model for a Global Dynamic Terrestrial Ecosystem Model II: Comparison to measurements," Agricultural Forest Meteorol., vol. 150, pp. 895-907, 2010. 
[20] D. J. Harding, M. A. Lefsky, G. G. Parker, and J. B. Blair, "Laser altimeter canopy height profiles: Methods and validation for closed-canopy, broadleaf forests," Remote Sens. Environ., vol. 76, pp. 283-297, 2001.

[21] M. A. Lefsky et al., "Lidar remote sensing of the canopy structure and biophysical properties of Douglas-fir western hemlock forests," Remote Sens. Environ., vol. 70, no. 3, pp. 339-361, Dec. 1999.

[22] S. Solberg et al., "Mapping LAI in a Norway spruce forest using airborne laser scanning," Remote Sens. Environ., vol. 113, pp. 2317-2327, 2009.

[23] J. B. Blair and M. A. Hofton, "Modeling laser altimeter return waveforms over complex vegetation using high-resolution elevation data," Geophys. Res. Lett., vol. 26, no. 16, pp. 2509-2512, Aug. 1999.

[24] K. D. Fieber et al., "Validation of canopy height profile methodology for small-footprint full-waveform airborne LiDAR data in a discontinuous canopy environment," ISPRS J. Photogramm. Remote Sens., vol. 104, pp. 144-157, Jun. 2015

[25] RIEGL, Riegl Website, Sep. 11, 2012. [Online]. Available: http://www. riegl.com

[26] O. Merlin et al., "The NAFE'06 data set: Towards soil moisture retrieval at intermediate resolution," Adv. Water Resources, vol. 31, pp. 1444-1455, 2008.

[27] R. Panciera et al., "The Soil Moisture Active Passive Experiments (SMAPEx): Toward soil moisture retrieval from the SMAP mission," IEEE Trans. Geosci. Remote Sens., vol. 52, no. 1, pp. 490-507, Jan. 2013.

[28] S. Solberg, E. Næsset, K. H. Hanssen, and E. Christiansen, "Mapping defoliation during a severe insect attack on Scots pine using airborne laser scanning," Remote Sens. Environ., vol. 102, no. 3/4, pp. 364-376, Jun. 2006

[29] M. A. White, G. P. Asner, R. R. Nemani, J. L. Privette, and S. W. Running, "Measuring fractional cover and leaf area index in arid ecosystems: Digital camera, radiation transmittance, and laser altimetry methods," Remote Sens. Environ., vol. 74, pp. 45-57, 2000.

[30] J. L. R. Jensen, K. S. Humes, L. A. Vierling, and A. T. Hudak, "Discrete return lidar-based prediction of leaf area index in two conifer forests," Remote Sens. Environ., vol. 112, no. 10, pp. 3947-3957, Oct. 2008.

[31] J. M. Chen and J. Cihlar, "Retrieving leaf area index of boreal conifer forests using Landsat TM images," Remote Sens. Environ., vol. 55, no. 2, pp. $153-162$, Feb. 1996

[32] K. D. Fieber and I. J. Davenport, CHP Toolkit, 2015. [Online]. Available: https://github.com/kdf200/CHP

[33] M. Isenburg, PulseWaves, 2015. [Online]. Available: https://github.com/ PulseWaves

[34] J. Armston et al., "Direct retrieval of canopy gap probability using airborne waveform lidar," Remote Sens. Environ., vol. 134, pp. 24-38, 2013.

[35] K. D. Fieber et al., "Analysis of full-waveform LiDAR data for classification of an orange orchard scene," ISPRS J. Photogramm. Remote Sens., vol. 82, pp. 63-82, Aug. 2013.

[36] W. Wagner, "Radiometric calibration of small-footprint full-waveform airborne laser scanner measurements: Basic physical concepts," ISPRS J. Photogramm. Remote Sens., vol. 65, no. 6, pp. 505-513, Nov. 2010.

[37] K. D. Fieber et al., "Preliminary leaf area index estimates from airborne small-footprint full-waveform lidar data," in Proc. IEEE IGARSS, Melbourne, Vic., Australia, 2013, pp. 3379-3382.

[38] J. L. Lovell, D. L. B. Jupp, D. S. Culvenor, and N. C. Coops, "Using airborne and ground-based ranging lidar to measure canopy structure in Australian forests," Can. J. Remote Sens., vol. 29, no. 5, pp. 607-622, Oct. 2003.

[39] J. D. Aber, "Method for estimating foliage-height profiles in broad-leaved forests," J. Ecol., vol. 67, no. 1, pp. 35-40, Mar. 1979.

[40] A. Monerris et al., "The third soil moisture active passive experiment," in Proc. 19th Int. Congr. Model. Simul., 2011, pp. 1980-1986.

[41] H. S. Black, Modulation Theory. New York, NY, USA: Van Nostrand, 1953.

Karolina D. Fieber received the M.Sc. degree in geoinformatics, photogrammetry, and remote sensing from the AGH University of Science and Technology, Krakow, Poland, in 2006 and the Ph.D. degree from the University of Reading, Reading, U.K., in 2015.

After a short Engineering and Physical Sciences Research Council Doctoral Prize Fellowship at the University of Reading, where she worked on airborne small-footprint full-waveform LiDAR data for vegetation characterization, she is now a Research Associate with Newcastle University, Newcastle, U.K. Prior to commencing her research career, she spent several years working in industry, with particular focus on photogrammetric documentation of architecture and cultural heritage.
Ian J. Davenport (M'04) received the Ph.D. degree in physics with astronomy from the University of London, London, U.K., in 1993.

He has conducted research at the National Environment Research Council's Unit for Thematic Information Studies, the Environmental Systems Science Centre, and the National Centre for Earth Observation at the University of Reading, Reading, U.K. He is currently with the Department of Geography and Environmental Science, University of Reading. His work has included the estimation of snow mass and soil moisture information from passive microwave observations and the extraction of land surface characteristics from airborne laser altimetry and synthetic aperture radar data.

James M. Ferryman (M'96) received the B.S. degree in computer science and the Ph.D. degree in computational vision from the University of Reading, Reading, U.K., in 1990 and 2000, respectively.

He became a Lecturer in computer science with the University of Reading in 1998, a Senior Lecturer in 2005, and a Full Professor in 2015. He currently leads the Computational Vision Group, School of Systems Engineering and has previously acted as the Director of Research with the School of Systems Engineering, University of Reading. He has participated in a wide range of U.K. and European Union (EU)-funded research programs, including the Engineering and Physical Sciences Research Council REASON Project (EP/C533402), which examined robust methods for monitoring and understanding people in public spaces, the EU Co-Friend Project (FP7-ICT-214975) on the construction of a cognitive platform for airport apron monitoring, and the EU FastPass Project (FP7-312583) on the development of a harmonized modular reference system for all European automated crossing points. He strongly supports technology transfer. He is the author of more than 100 scientific publications. His current research interests include remote sensing, automated closed-circuit television surveillance of public spaces, behavioral analysis, biometrics, robotics and autonomous systems, novel imaging modalities, and performance evaluation

Dr. Ferryman is a member of the British Computer Society and has acted as the Director of both the British Machine Vision Association and the Security Information Technology Consortium. Since 2000, he has been a Cochair of the IEEE International Workshop on Performance Evaluation of Tracking and Surveillance.

Robert J. Gurney received the Ph.D. degree from the University of Bristol, Bristol, U.K., in 1975.

For five years, he spent his research career with the Institute of Hydrology, Wallingford, U.K. For ten years, he was with the Hydrological Sciences Branch of the NASA Goddard Space Flight Center, five years of which he spent as the Branch Head. In 1990, he became a Professor with the University of Reading, Reading, U.K., and concurrently served as the Director of the Natural Environment Research Council's (NERC) Unit for Thematic Information Systems and, in 1995, the Director of the NERC Environmental Systems Science Centre. He stepped down from this role in 2012 and is currently a Professor of Earth Observation Science with the School of Mathematical and Physical Sciences, University of Reading. Throughout his career, he has been involved in many satellite missions, including most recently the NASA Soil Moisture Active Passive mission. His research interests include the use of Earth observation in land surface modeling and of many types of data to constrain land surface models.

Victor M. Becerra (SM'03) received the Ph.D. degree in control engineering from City University London, London, U.K., in 1994.

$\mathrm{He}$ is currently a Professor of power systems engineering with the School of Engineering, University of Portsmouth, Portsmouth, U.K. Between 1989 and 1991, he was an Electrical Engineer with C.V.G. Edelca, Caracas, Venezuela. Between 1994 and 1999, he was a Postdoctoral Research Fellow with the Control Engineering Research Centre, City University London. Between 2000 and 2015, he was an academic with the School of Systems Engineering, University of Reading, Reading, U.K. During his career, he has received research funding from the Engineering and Physical Sciences Research Council, the Royal Academy of Engineering, the European Space Agency, the Technology Strategy Board, the European Union, and the U.K. industry. His current research interests consider a range of issues related to electrical power systems and the methods and applications of automatic control. These interests include control of power systems, energy storage and its integration to power grids, computational intelligence for smart grids, computational optimal control, nonlinear control, state estimation, and robotics.

Dr. Becerra is a Fellow of the Institution of Engineering and Technology. 
Jeffrey P. Walker (M'13-SM'15) received the B.E. (Civil) and B.Surv. degrees (with Hons 1 and University Medal) and the Ph.D. degree in water resources engineering from the University of Newcastle, Callaghan, Australia, in 1995 and 1999, respectively. His Ph.D. thesis was among the early pioneering research on the estimation of root-zone soil moisture from assimilation of remotely sensed surface soil moisture observations.

He then joined the NASA Goddard Space Flight Center to implement his soil moisture work globally. In 2001, he moved to the Department of Civil and Environmental Engineering, University of Melbourne, Melbourne, Australia, as a Lecturer, where he continued his soil moisture work, including the development of the only Australian airborne capability for simulating new satellite missions for soil moisture. In 2010, he was appointed as a Professor in the Department of Civil Engineering, Monash University, Clayton, Australia, where he is continuing research work. He is contributing to soil moisture satellite missions at NASA, ESA, and JAXA, as a Science Team Member for the Soil Moisture Active Passive mission and a Cal/Val Team Member for the Soil Moisture and Ocean Salinity mission and the Global Change Observation Mission-Water mission, respectively.
Jörg M. Hacker received the Dr.rer.nat. degree in atmospheric sciences from the Meteorological Institute, University of Bonn, Bonn, Germany, in 1980.

Since 1982, he has been with Flinders University, Adelaide, South Australia, where he built Australia's National Research Aircraft Facility Airborne Research Australia (ARA), which today is Australia's only National Facility engaged in using and operating aircraft for atmospheric and environmental research. He is currently ARA's Director and Chief Scientist and a Professor of airborne research with Flinders University. He pioneered the concept of using cost-efficient small aircraft for atmospheric research, including the research described in this paper. He holds a pilot's license with several special endorsements and has more than 7000 flying hours in a wide range of aircraft, including flying gliders over the Andes in South America up to $12.5 \mathrm{~km}$. 